\title{
BULLA BONIFATII PP. IX FACULTATEM THEOLOGICAM IN STUDIO GENERALI CRACOVIENSI INSTITUENS
}

Bonifacius episcopus servus servorum Dei. Ad perpetuam rei memoriam. / Eximie devotions affectus, quem carissimus in Christo filius noster Wladislaus Rex et carissima in Christo filia nostra Hedwigis Regina / Polonie illustres ad nos et Romanam gerunt ecclesiam, promeretur, ut votis eorum, illis presertim, per que divini nominis et / fidei catholice cultus protenditur, iustitia colitur, tam publica quam privata res geritur utiliter, omnisque prosperitas humane conditionis / augetur, favorabiliter annuamus. Cum itaque sicut exhibita nobis nuper pro parte dictorum Regis et Regine petitio contine/bat, in eorum civitate Cracoviensi ex statuto et ordinatione sedis apostolice ab olim fuerit atque sit in utroque iure et alia qualipbet licita facultate, preterquam in sacra theologia, studium generale: pro parte Regis ac Regine predictorum nobis fuit humiliter / supplicatum, ut in civitate predicta statuere et ordinare huiusmodi studium generale etiam in ipsa theologia de benignitate / apostolica dignaremur. Nos igitur huiusmodi supplicationibus inclinati auctoritate apostolica tenore presentium statuimus et etiam / ordinamus, quod in ipsa civitate exnunc inantea perpetuis futuris temporibus sit ac esse valeat etiam in eadem theologia hu/iusmodi studium generale, cui presit is, qui eidem studio hactenus prefuit ab antiquo. Et nihilominus de uberioris do/no gratie concedimus, quod studentes et regentes pro tempore in ipso studio in eadem theologia, ac bacallariatus, licentie vel / doctoratus gradum ibidem suscipientes, omnibus privilegije, libertatibus, prerogativis et indulgentija gaudeant et utantur, qui/ bus quacunque auctoritate concessis in eadem theologia studentes, regentes et similes gradus Parisiis suscipiens / gaudent ac etiam quomodolibet potiuntur. Nulli ergo omnino hominum liceat hanc paginam nostrorum statuti, ordinatio/nis et concessionis infringere vel ei ausu temerario contraire. Siquis autem hoc attemptare presumpserit, indignationem / omnipotentis dei et beatorum Petri et Pauli Apostolorum eius se noverit incursurum. Datum Rome apud Sanctum Petrum / III Idus Ianuarii, pontificatus nostri anno octavo. 